\title{
Credit Constraints, Firms' Precautionary Investment, and the Business Cycle*
}

\author{
Ander Perez \\ Universitat Pompeu Fabra and Barcelona GSE
}

September 15, 2010

\begin{abstract}
This paper studies the macroeconomic implications of firms' precautionary investment behavior in response to the anticipation of future financing constraints. Firms increase their demand for liquid and safe investments in order to alleviate future borrowing constraints and decrease the probability of having to forego future profitable investment opportunities. This results in an increase in the share of short-term projects that produces a temporary increase in output, at the expense of lower long-run investment and future output. I show in a calibrated model that this behavior is at the source of a novel and powerful channel of shock transmission of productivity shocks that produces short-run dampening and long-run propagation. Furthermore, it can account for the observed business cycle patterns of the aggregate and firm-level composition of investment.

Keywords: Investment Choice, Financial Frictions, Business Cycles, Idiosyncratic Production Risk
\end{abstract}

JEL Classification Numbers: D92, E22, E32, G32

${ }^{*}$ I am grateful to Kosuke Aoki and Nobu Kiyotaki for very valuable discussions, and for very helpful comments Vicente Cunat, Wouter den Haan, Antoine Faure-Grimaud, Roman Inderst, Eric Leeper, Albert Marcet, Raoul Minetti, Alex Michaelides, Javier Suarez, Aleh Tsyvinski, David C. Webb, Alwyn Young and seminar participants in LSE, HEC Montreal, Indiana, CEMFI, Bank of Spain, Alicante, Carlos III, Autonoma de Barcelona - IAE-CSIC, Bank of Italy, Tilburg, Cambridge, Birkbeck, Pompeu Fabra, Bank of England, the Society for Computational Economics Meetings 2007 (Montreal), the Econometric Society Summer Meetings 2007 (Duke), and the Society for Economic Dynamics Meetings 2010 (Montreal). 


\section{Introduction}

Firms typically face a choice between multiple projects when deciding how to invest and financing constraints may impact this decision in two ways. If there are financing shortages in the present the firm will tend to, all else equal, favor projects that attract more external finance than others. If firms instead anticipate future financing constraints, and to the extent that these are costly, they may prefer projects that produce earlier or safer returns that do not compromise the future strength of their balance sheet. Indeed, firm managers typically cite as one of their main concerns the availability of future resources to avoid financial distress and to be able to benefit from profitable investment opportunities, and empirical evidence suggests that firms' precautionary behavior in anticipation of future expected financial constraints is a key determinant of their investment and operating decisions. ${ }^{1}$

The concern for whether financing constraints significantly affect the type of investment firms carry out is supported by empirical evidence on the compositional dynamics of investment. Aghion, et al. (2007) find using a firm-level data-set that while the share of R\&D investment over total investment is countercyclical for firms that do not face credit constraints, it becomes pro-cyclical for credit constrained firms. At the aggregate level, Aghion, et al. (2010) provide evidence using data on the composition of investment of a panel of countries that the share of structural (long-term) investment over total investment decreases following shocks that can be expected to make firms more likely to be credit constrained in the near future, and also document that this effect is stronger for less financially developed economies.

In this paper we perform a quantitative theoretical exploration of the implications for aggregate investment and output dynamics of the joint consideration of investment choice and financing constraints in an intertemporal setup which allows for a precautionary investment behavior of firms that anticipate future financial constraints. Does the combination of investment choice and financing constraints in firms act to dampen or amplify the effects of aggregate shocks? Do financial frictions impact how much aggregate investment occurs in relatively more productive long-term projects in such a way that shocks are propagated through time? And finally, can a model with these ingredients account for the behavior of the composition of investment across the business cycle? These questions are dealt with by analyzing a dynamic stochastic general equilibrium model of a production economy subject to aggregate and idiosyncratic uncertainty. In the model, risk-neutral entrepreneurs produce capital to be used by consumption good producing firms. Entrepreneurs have access every period to a safe but lowreturn short-term technology that produces capital goods, and also to a highly profitable risky technology that performs research and development $(\mathrm{R} \& \mathrm{D})$ and produces positive long-term spillovers on other entrepreneurs' capital-producing technology. They may suffer from credit constraints when seeking external finance; investment in R\&D does not generate collateral and cannot attract external finance, while the safe investment generates a positive and endogenous

\footnotetext{
${ }^{1}$ Surveys by Graham and Harvey (2001) and Bancel and Mittoo (2004) find that CFOs consider financial flexibility (having enough internal funds to avoid having to fore-go positive Net Present Value projects in the future) to be the primary determinant of their policy decisions. Almeida, Campello and Weisbach (2004) report that the expectation of future financing problems significantly affects firms' investment policies, and Caggese and Cunat (2007) find that it significantly impacts hiring decisions.
} 
amount of pledgeable output.

Entrepreneurs have an incentive to shift investment towards the risky project in recessions because its returns are relatively acyclical whereas short term activities offer poor returns in downturns. However, given that they can only pledge the returns of their short-run safe investments as collateral this means that in recessions they produce less pledgeable output and can borrow less per unit of investment, resulting in countercyclical credit constraints. This explanation for the countercyclicality of financing constraints is the first result of the paper and provides an alternative to the two main explanations offered in the literature that ascribe the countercyclicality of financing problems to countercyclical agency $\operatorname{costs}^{2}$ or to collateral constraints and lack of indexation of debt contracts ${ }^{3}$.

The second and main contribution of the paper is the description and quantitative evaluation of a novel amplification and propagation mechanism of shocks based on the precautionary investment behavior of firms. If a negative aggregate productivity shock hits the economy, entrepreneurs anticipate its effects to persist and the probability of facing credit constraints in future periods to increase. Despite risk-neutral preferences, the combination of credit constraints and decreasing returns to scale production functions generates an effective risk aversion that reduces the willingness of entrepreneurs to shift investment towards $R \& D$ as this may aggravate future financing problems. This means that, relative to the unconstrained scenario in which investment in the safe capital-production technology drops strongly, safe investment does not fall as much, acting to dampen the contemporaneous effect of the shock; the short-run supply of capital from entrepreneurs does not decrease as much as it does in the unconstrained case. In other words, intertemporal optimization in the presence of finance constraints increases the incentive to invest more in activities that produce output sooner, thus cushioning the effect of any shock on impact. In the benchmark calibration the contemporaneous reaction of output is around 30\% smaller than the one obtained in a version of the model with no financing constraints. The simultaneous decrease in investment in the highly productive risky $R \& D$ technology has negative long-term consequences, however, as it translates into less spillover effects into other entrepreneurs and a decrease in average productivity in the medium and longrun. This second mechanism adds propagation to the effects of shocks. In summary, a tradeoff arises between contemporaneous amplification and long-term propagation of the effects of shocks; stronger dampening is associated to larger propagation. We show in the calibrated model that these dampening and propagation effects of entrepreneurs' precautionary behavior are quantitatively significant.

At the heart of the quantitative relevance of the proposed mechanism is the idea that despite the fact that a small fraction of agents are observed to be financially constrained at any given point in time, a much larger fraction may anticipate the possibility of being constrained in the future. The importance of this distinction between the effect of the anticipation of future binding constraints and the contemporaneous effect of currently binding constraints was pointed out long ago in the literature on consumption in the presence of borrowing constraints. ${ }^{4}$

The third main result is that this model is able to characterize how financing constraints

\footnotetext{
${ }^{2}$ As in Bernanke and Gertler (1989), Carlstrom and Fuerst (1997), or Christiano, Motto and Rostagno (2008).

${ }^{3}$ As in Kiyotaki and Moore (1997) or Iacoviello (2005).

${ }^{4}$ See Zeldes (1989).
} 
impact the business cycle pattern of the composition of investment. Binding financing constraints make the share of less collateralizable projects procyclical, irrespective of risk, while the anticipation of future constraints makes the share of risky projects procyclical, irrespective of the ability to collateralize such projects. To the extent that risk and pledgeability are not perfectly related in many investment projects this introduces a way to empirically distinguish between the relative importance of contemporaneously binding credit constraints and future expected constraints.

\section{Relationship with the Literature}

A large body of research has studied the role of firms' financing frictions in amplifying business cycles. Most of this work focuses on how firms' investment capacity is affected by tighter borrowing constraints in recessions or following a tightening of monetary policy, either directly through a balance sheet channel (Bernanke and Gertler (1989), Kiyotaki and Moore (1997), Bernanke, Gertler and Gilchrist (1999)) or indirectly through a decreased supply of intermediated finance (Holmstrom and Tirole (1997), Van den Heuvel (2007)). Common to most of these models is the assumption that firms can invest in only one type of project, and this has two undesirable consequences for our purposes in this paper. First, by construction, questions regarding composition of investment cannot be addressed. Second, because of the assumption in most of these models of permanently binding credit constraints, the effect of the anticipation of future constraints is limited to general equilibrium effects that affect entrepreneurs through asset prices. But entrepreneurs who anticipate future constraints and have an incentive to insure against them are unable to do so because their possible actions are limited to investing as much as their (permanently binding) constraints allow in their single investment opportunity.

Two closely related papers are Matsuyama (2007) and Aghion et al. (2010), who both address the composition of investment in models with financial constraints. Matsuyama (2007) studies how financing constraints affect the allocation of credit to different sectors, but only considers the effect of currently binding constraints and not how the expectation of future constraints may impact investment patterns today. Aghion et al. (2010) study the effect of financial frictions on the dynamics of short-run versus long-run investment across the business cycle. Long term highly-productive investment projects are a source of liquidity risk which means they may have to be discontinued mid-way should the firm run into financing constraints, so financial frictions discourage investment in long-term projects (lower mean growth) and tend to make them procyclical (higher volatility). A number of considerations distinguish their work from this paper. First, they ignore the effects of risk which are central to the mechanism described in this paper. Second, the implication in their model of a larger share of long-term investment is a contemporaneous increase in productivity, while the implication in our paper of a larger share of risky illiquid investment is a delayed and protracted increase in productivity and a contemporaneous drop in productivity due to a smaller share invested in safe short term projects. Third, constraints are not allowed in their model to bind contemporaneously, as opposed to mine. Finally, this paper is able to do a quantitative evaluation of the importance of this mechanism by studying it in the context of a fully fledged general equilibrium model.

This paper is also related to a strand of literature that studies the macroeconomic impact of uninsurable investment risk (Acemoglu and Zilibotti (1997), Angeletos and Calvet (2006)) 
in the neoclassical growth model, to analyze issues related to capital accumulation, equilibrium real interest rates and output growth rates.

Finally, a number of theoretical papers in the corporate finance literature have also identified the possibility that finance constraints in an intertemporal setting may generate risk aversion in entrepreneurs with otherwise risk-neutral preferences. If firms face costs of raising external finance they may find it optimal to hedge against low cash-flow realizations to avoid having to fore-go positive NPV projects (Froot, Scharfstein and Stein (1993)) or to avoid non-linear costs of financial distress (Stulz (1984)).

The remainder of the paper is organized as follows. Section 2 studies in detail the problem faced by entrepreneurs in a partial equilibrium set-up. Section 3 embeds this analysis in a fully general equilibrium dynamic stochastic model. The steady state of the model, and the calibration, are discussed in section 4 . Section 5 presents the main results of the model, and section 6 evaluates the robustness of these results. Finally, section 7 concludes.

\section{Partial Equilibrium Model of Entrepreneurial Investment}

In this section we develop and study a partial equilibrium model of entrepreneurial investment, which will be embedded into a general equilibrium framework in section 3 . We postpone the detailed analysis of the complete economy setup to that section and here we just provide a brief sketch for the benefit of clarity. We consider an infinite horizon discrete-time economy populated by three types of agents: households, entrepreneurs and firms. Entrepreneurs constitute the capital-producing sector of the economy and may face financial constraints, and firms form the consumption-good producing sector and do not suffer from financing frictions.

Returning to the detailed analysis of entrepreneurs, these are modeled as overlapping generations of two-period lived agents, so that at any point in time two generations, which we will label "young" and "old", coexist. Entrepreneurs only consume at the end of their old period and are risk neutral.

\subsection{Investment opportunities}

An entrepreneur (young or old) alive in period $t$ can invest simultaneously in two different technologies, a safe and a risky one. The safe one produces capital using consumption goods as the sole input. This capital is then sold at price $q_{t}$ to households to be rented to consumption good producing firms who use it as a factor of production. Investing an amount $i_{s, t}$ ( $s$ for "safe") of consumption goods delivers an amount $j_{t} z_{e} i_{s, t}+j_{t} z_{s} i_{s, t}^{\alpha}$ of capital goods with certainty within the same period, which after being sold generates revenues of $q_{t} j_{t} z_{e} i_{s, t}+q_{t} j_{t} z_{s} i_{s, t}^{\alpha}$. The relevance of having a production function with two additive terms will become clearer later on when we introduce credit constraints; the first term will capture the pledgeable part of output that can be borrowed against, and can be interpreted as a part of output that is delivered first and thus provides early liquidity. The parameters $z_{e}$ and $z_{s}$ determine the productivity associated to the early and regular parts of production respectively, and $j_{t}$ is a time-varying productivity factor 
that captures technological spillovers from other firms and which will be discussed in more detail in the following section dealing with general equilibrium.

Entrepreneurs can also invest in a risky technology that produces research and development (R\&D). Investing an amount $i_{r, t}(r$ for "risky") of consumption goods delivers an amount $\left(1+\varepsilon_{t^{+}}\right) z_{r} i_{r, t}^{\alpha}$ units of the consumption good, where $\varepsilon_{t^{+}} \sim U(-\sigma, \sigma)$, with $\sigma \geq 1$, captures idiosyncratic uncertainty, which is resolved during the period and after decisions have been made by the entrepreneur (and hence at a moment in time denoted $t^{+}$). The exact process that transforms consumption goods into $\mathrm{R} \& \mathrm{D}$, and the market in which $\mathrm{R} \& \mathrm{D}$ is sold to obtain revenues in terms of consumption goods, are left unmodeled as they are not the focus of this paper.

The interpretation of the differences between both technologies could be broad and is meant to capture primarily the dimensions of risk, pledgeability and maturity. The capital-producing technology is safe, produces output in the short-term, and a fraction of the output it produces can be pledged to outside financiers, while $R \& D$ is risky, has long-term spillover effects, and has to be financed entirely by internal resources. Examples of the first could be purchasing new IT equipment, expanding an existing production plant, or accumulating inventories, while examples of the second could be research \& development or advertising expenses. For the remainder of the paper we will identify the safe technology as physical investment (machinery, plants and equipment) and the risky technology as $\mathrm{R} \& \mathrm{D}$ and later on we will compare the behavior of these variables to that of fixed capital formation and $R \& D$ in the data.

\subsection{First-Best Solution}

As discussed above, an entrepreneur born in period $t$ will make a first investment choice at the beginning of $t$ and a second one, when old, at the beginning of period $t+1$, and the investment options are identical in both periods. Absent any borrowing constraints, young and old entrepreneurs simply maximize expected profits $\pi_{t}$ each period, where the expectation is taken only over the idiosyncratic risk term $\left(1+\varepsilon_{t^{+}}\right)$, where $E_{t}\left(1+\varepsilon_{t^{+}}\right)=1$, and not over aggregate uncertainty, as production takes place within the period once aggregate uncertainty is resolved. Young and old entrepreneurs thus perform the following maximization:

$$
\max _{i_{s, t}, i_{r, t}} q_{t} j_{t} z_{e} i_{s, t}+q_{t} j_{t} z_{s} i_{s, t}^{\alpha}+z_{r} i_{r, t}^{\alpha}-b_{t}
$$

subject to the first period budget constraint

$$
i_{s, t}+i_{r, t}=n_{t}+b_{t}
$$

where $n_{t}$ is entrepreneurs' start-of-period wealth. For the young entrepreneurs, $n_{t}$ will arise from wage payments, as they are assumed to be endowed when young with one unit of labor which they provide to the firms in exchange for a wage $w_{t}^{e}$. For the old entrepreneurs, $n_{t}$ will be the net worth brought over from their young period. On the other hand, $b_{t}$ is the borrowing entrepreneurs can undertake to finance their investment. Entrepreneurs are assumed to be able to borrow from households using intra-period debt contracts. The fact that borrowing and 
repayment occur within the period means that the interest rate charged on debt will be zero, as households have no alternative use for those funds during such a short period of time. Negative values of $b_{t}$ reflect storage of consumption goods at a zero rate of return. In this unconstrained scenario $b_{t}$ is allowed to be state-contingent; $b_{t}$ thus reflects the expected repayments from the entrepreneur to households.

Entrepreneurs, young and old, will simply invest up to the optimal unconstrained scale in both their young and old ages. Modigliani-Miller conditions apply and balance sheet conditions (in particular, the level of entrepreneurial net worth) are irrelevant for real outcomes. In period $t$, the optimal investment scale (for young or old) is given by:

$$
i_{s, t}^{f b}=\left(\frac{\alpha q_{t} j_{t} z_{s}}{1-q_{t} j_{t} z_{e}}\right)^{\frac{1}{1-\alpha}}
$$

and

$$
i_{r, t}^{f b}=\left(\alpha z_{r}\right)^{\frac{1}{1-\alpha}}
$$

where $f b$ denotes "first best". The resulting ratio of risky to safe investment is:

$$
\left(\frac{i_{r, t}}{i_{s, t}}\right)_{f b}=\left(\frac{z_{r}}{q_{t} j_{t} z_{s}}-\frac{z_{r} z_{e}}{z_{s}}\right)^{\frac{1}{1-\alpha}} .
$$

One of the objectives of this paper is to study the cyclical behavior of the composition of entrepreneurial investment, which is given by the ratio in expression (3). The two variables which affect this ratio are $q_{t}$ and $j_{t}$. To the extent that $q_{t}$, the price of capital, varies procyclically, this will make the ratio countercyclical. In other words, in a world without credit constraints the share of R\&D over total investment increases in downturns. In good times, the safe return is high $\left(q_{t+1}\right.$ is high) and its relative profitability with respect to the risky expected return increases, given that the expected return to $R \& D$ remains constant and is not affected by the business cycle. This feature of the risky technology is meant to capture the idea that R\&D is a long-term investment that will provide a significant share of its returns far into the future and is thus not affected by current business conditions. This will be called the opportunity cost effect, and follows the Schumpeterian view of recessions as "cleansing periods". The behavior of $j_{t}$, and its impact on this ratio, will be analyzed later.

\subsection{Credit constraints and Precautionary Behavior}

The amount entrepreneurs can borrow will be limited by the amount of end-of-period wealth they can pledge to beginning-of-period lenders. We assume that they can only credibly pledge to repay an amount of debt smaller than or equal to the early part of the output arising from the safe capital-producing technology, so that

$$
b_{t} \leq q_{t} j_{t} z_{e} i_{s, t}
$$

There are at least two possible justifications for this particular form of constraint. The first one relies on two agency problems; households' lack of ability to verify entrepreneurs' returns and 
to enforce entrepreneurs' debt obligations. The inability to verify returns renders risky returns non-pledgeable by allowing entrepreneurs to lie to households about their risky returns and claim they have had none (zero risky returns are always a possibility given that $\sigma \geq 1$ ). Limited contract enforceability may limit how much entrepreneurs can pledge of the safe returns. The assumption made is either that early returns are harder to divert, or that there is no incentive to divert them given that it would mean production has to be discontinued. Once the entrepreneur holds the total returns from the safe activity, he could choose to default on any debt obligations. For this reason, borrowing is limited to the early revenues the entrepreneur can obtain and can repay the lender prior to completing his production. Following this interpretation, parameter $z_{e}$ captures the degree of pledgeability of the safe returns.

A second rationalization sees the early returns as liquidity which can be reinvested in the firm, which is isomorphic to being able to borrow that same amount at a zero interest rate.

As opposed to the unconstrained case, choices entrepreneurs make when young will affect their investment choices when old because of credit constraints. A young entrepreneur in period $t$ will maximize expected profits in $t+1$ :

$$
\max _{i_{s, t}, i_{r, t}, b_{t}, i_{s, t+1}, i_{r, t+1}, b_{t+1}} E_{t}\left(\pi_{t+1}\right),
$$

where

$$
\pi_{t+1}=q_{t+1} j_{t+1} z_{s} i_{s, t+1}^{\alpha}+q_{t+1} z_{e} i_{s, t+1}+\left(1+\varepsilon_{(t+1)^{+}}\right) z_{r} i_{r, t+1}^{\alpha}-b_{t+1},
$$

subject to budget constraints for their young and old age, respectively:

$$
\begin{aligned}
i_{s, t}+i_{r, t} & =n_{t}+b_{t}, \\
i_{s, t+1}+i_{r, t+1} & =q_{t} z_{s} i_{s, t}^{\alpha}+q_{t} z_{e} i_{s, t}+\left(1+\varepsilon_{t^{+}}\right) z_{r} i_{r, t}^{\alpha}-b_{t}+b_{t+1},
\end{aligned}
$$

and subject to a borrowing constraint for each of the two periods:

$$
\begin{aligned}
b_{t} & \leq q_{t} z_{e} i_{s, t}, \\
b_{t+1} & \leq q_{t+1} z_{e} i_{s, t+1} .
\end{aligned}
$$

Now the time $t$ expectation of time $t+1$ revenues is taken over both idiosyncratic and aggregate uncertainty.

In any given period, financing constraints bind when the unconstrained optimal investment level, net of the borrowing it can generate, cannot be covered by internal resources $n_{t}$. The threshold below which internal resources are insufficient, $n_{t}^{*}$, is:

$$
n_{t}^{*}=\left(\frac{\alpha q_{t} j_{t} z_{s}}{1-q_{t} j_{t} z_{e}}\right)^{\frac{1}{1-\alpha}}+\left(\alpha z_{r}\right)^{\frac{1}{1-\alpha}}-q_{t} j_{t} z_{e}\left(\frac{\alpha q_{t} j_{t} z_{s}}{1-q_{t} j_{t} z_{e}}\right)^{\frac{1}{1-\alpha}},
$$

where the first two terms on the right hand side capture the unconstrained optimal investment level requirements, and the third term is the maximum borrowing possible under that level of investment. 
An inspection of expression (10) gives us some insight into the model's predictions about the cyclicality of credit constraints. The specification of production opportunities introduced in this model offers one new important reason why credit constraints may worsen during downturns. As we discussed when analyzing the unconstrained case, an opportunity cost effect introduces an incentive in recessions to shift production towards the less pledgeable risky technology. This means that, for a given level of investment, the shift in the mix of types of investments is such that entrepreneurs are generating less pledgeable output and thus being able to borrow less. This is a novel theoretical justification for the countercyclicality of constraints.

On top of this, the collateral value of output, driven by $q_{t}$, decreases and internal resources, captured by $n_{t}$, are also lower in recessions. All these three factors concur to generate countercyclical credit constraints.

We will assume that young entrepreneurs are always credit constrained. ${ }^{5}$ This assumption is justified by the idea that young entrepreneurs represent start-up firms with limited access to finance. They may however become unconstrained by the second period if they obtain sufficiently high returns on their investments. The net worth with which they will enter their old age follows a uniform distribution $n_{t+1} \sim U\left(n_{t+1}^{\min }, n_{t+1}^{\max }\right)$, where:

$$
\begin{aligned}
n_{t+1}^{\max } & =q_{t} j_{t} z_{s} i_{s, t}^{\alpha}+(1+\sigma) z_{r} i_{r, t}^{\alpha} \\
n_{t+1}^{\min } & =q_{t} j_{t} z_{s} i_{s, t}^{\alpha}+(1-\sigma) z_{r} i_{r, t}^{\alpha} .
\end{aligned}
$$

They will be financially unconstrained as long as $n_{t+1} \geq n_{t+1}^{*}$ and constrained otherwise. The probability of being credit constrained in the old age, conditional on the choices of $i_{s, t}$ and $i_{r, t}$, is thus:

$$
\operatorname{Pr}_{n_{t+1} \leq n_{t+1}^{*}}\left(i_{s, t}, i_{r, t}\right)=\frac{E_{t}\left(n_{t+1}^{*}\right)-n_{t+1}^{\min }}{n_{t+1}^{\max }-n_{t+1}^{\min }}
$$

If entrepreneurs end up being unconstrained in their old age, they will invest according to the first best investment scale studied before. If, however, they end up being credit constrained, they will solve the following maximization in $t+1$ :

$$
\max _{i_{s, t+1}, i_{r, t+1}} q_{t+1} j_{t+1} z_{s} i_{s, t+1}^{\alpha}+q_{t+1} j_{t+1} z_{e} i_{s, t+1}+z_{r} i_{r, t+1}^{\alpha}-b_{t+1},
$$

subject to a budget constraint and a binding borrowing constraint

$$
\begin{gathered}
i_{s, t+1}+i_{r, t+1}=n_{t+1}+b_{t+1} \\
b_{t+1}=q_{t+1} j_{t+1} z_{e} i_{s, t+1},
\end{gathered}
$$

which simplifies to

\footnotetext{
${ }^{5}$ I check that this assumption is met endogenously in the neighborhood of the steady state of the economy in numerical simulations carried out under the calibration discussed in section 4.
} 


$$
\max _{i_{s, t+1}, i_{r, t+1}} q_{t+1} j_{t+1} z_{s} i_{s, t+1}^{\alpha}+z_{r} i_{r, t+1}^{\alpha}
$$

subject to

$$
\left(1-q_{t+1} j_{t+1} z_{e}\right) i_{s, t+1}+i_{r, t+1}=n_{t+1}
$$

The first order conditions for this problem imply the following optimal choices:

$$
\begin{aligned}
i_{s, t+1}^{o c} & =\frac{\left[z_{r}\left(1-q_{t+1} j_{t+1} z_{e}\right)\right]^{\frac{1}{\alpha-1}}}{\left(q_{t+1} j_{t+1} z_{s}\right)^{\frac{1}{\alpha-1}}+z_{r}^{\frac{1}{\alpha-1}}\left(1-q_{t+1} j_{t+1} z_{e}\right)^{\frac{\alpha}{\alpha-1}}} n_{t+1} \\
i_{r, t+1}^{o c} & =\left[1-\left(1-q_{t+1} j_{t+1} z_{e}\right) \lambda_{t+1}\right] n_{t+1}
\end{aligned}
$$

where the superscript oc stands for "old constrained".

Bringing everything together, we can now write down the simplified two period optimization problem that a young entrepreneur has to solve, when he faces a probability of still remaining credit constrained when old given by (11) and under the assumption that he is credit constrained when young. The entrepreneur will be maximizing expected profits when old, given by:

$$
\max _{i_{s, t}, i_{r, t}} E_{t}\left[\int_{n_{t+1}^{*}}^{n_{t+1}^{\max }} \pi_{t+1}^{f b}\left(n_{t+1}\right) f\left(n_{t+1}\right) d n_{t+1}+\int_{n_{t+1}^{\min }}^{n_{t+1}^{*}} \pi_{t+1}^{o c}\left(n_{t+1}\right) f\left(n_{t+1}\right) d n_{t+1}\right]
$$

where the expectation is taken over aggregate uncertainty (which affects the entrepreneur in his old age through uncertainty about $q_{t+1}$ and $j_{t+1}$ ). The first integral captures those states in which the entrepreneur is unconstrained and will obtain a profit $\pi_{t+1}^{f b}\left(n_{t+1}\right)$ associated to the first best investment scale. The second integral captures those states in which the entrepreneur is credit constrained and only obtains profits $\pi_{t+1}^{o c}\left(n_{t+1}\right)$, and $f\left(n_{t+1}\right)$ is the distribution function of $n_{t+1}$.

Given what we know about the investment pattern of the unconstrained entrepreneurs and the old constrained entrepreneurs, the objective function can be expressed as:

$$
\begin{aligned}
& \max _{i_{s, t}, i_{r, t}} E_{t}\left[\operatorname{Pr}\left(n_{t+1}>n_{t+1}^{*}\right)\left(\psi_{t+1}+\frac{n_{t+1}^{\max }}{2}\right)\right] \\
& +E_{t}\left[\frac{q_{t+1} j_{t+1} z_{s} \lambda_{t+1}^{\alpha}+z_{r} \chi_{t+1}^{\alpha}}{n_{t+1}^{\max }-n_{t+1}^{\min }} \int_{n_{t+1}^{\min }}^{n_{t+1}^{*}} n_{t+1}^{\alpha} d n_{t+1}\right],
\end{aligned}
$$

where 


$$
\begin{aligned}
n_{t+1} & =q_{t} j_{t} z_{s} i_{s, t}^{\alpha}+\left(1+\varepsilon_{t^{+}}\right) z_{r} i_{r, t}^{\alpha}, \\
n_{t+1}^{\max } & =q_{t} j_{t} z_{s} i_{s, t}^{\alpha}+(1+\sigma) z_{r}\left[n_{t}-\left(1-q_{t} j_{t} z_{e}\right) i_{s, t}\right]^{\alpha}, \\
n_{t+1}^{\min } & =q_{t} j_{t} z_{s} i_{s, t}^{\alpha}+(1-\sigma) z_{r}\left[n_{t}-\left(1-q_{t} j_{t} z_{e}\right) i_{s, t}\right]^{\alpha}, \\
\lambda_{t+1} & =\frac{\left[z_{r}\left(1-q_{t+1} j_{t+1} z_{e}\right)\right]^{\frac{1}{\alpha-1}}}{\left(q_{t+1} j_{t+1} z_{s}\right)^{\frac{1}{\alpha-1}}+z_{r}^{\frac{1}{\alpha-1}}\left(1-q_{t+1} j_{t+1} z_{e}\right)^{\frac{\alpha}{\alpha-1}}}, \\
\chi_{t+1} & =1-\left(1-q_{t+1} j_{t+1} z_{e}\right) \lambda_{t+1},
\end{aligned}
$$

and

$$
\psi_{t+1}=q_{t+1} j_{t+1} z_{s} i_{s, t+1}^{f b \alpha}+q_{t} j_{t+1} z_{e} i_{s, t+1}^{f b}+z_{r} i_{r, t+1}^{f b \alpha}-i_{s, t+1}^{f b}-i_{r, t+1}^{f b}+\frac{n_{t+1}^{*}}{2}
$$

Finally, the entrepreneur will be subject to his first period budget constraint:

$$
i_{s, t}+i_{r, t}=n_{t}+q_{t} j_{t} z_{e} i_{s, t}
$$

The potential for binding constraints in some future states of nature introduces an important non-linearity in the relationship between the net worth $n_{t+1}$ entrepreneurs transfer into their second period and returns from investment in that period. As can be seen in expression (13), profits in period $t+1$ in states in which the entrepreneur is unconstrained are linear in beginningof-period wealth $n_{t+1}$, while they are concave in $n_{t+1}$ in those states in which credit constraints bind. A number of implications follow from this. First, an entrepreneur that does not expect any borrowing constraints in the future does not care about the risk associated to his first period investment; he will simply maximize expected returns. Second, the potential for future credit constraints introduces a motive for risk management and discourages risky investment by the entrepreneur. We will call this the precautionary effect. Third, to the extent that the likelihood of being credit constrained is higher in downturns, this production-related risk aversion increases in downturns, acting as a force that deters investment in R\&D in downturns. Whether R\&D as a share of total investment is procyclical or countercyclical will depend on the strength of the two opposing forces, the opportunity cost effect discussed before that generates countercyclicality and the precautionary effect just described that generates procyclicality.

It is worth noting that any motive for risk aversion in this model arises from productionrelated factors and does not arise from entrepreneurs' preferences, which are assumed to be riskneutral. This is especially interesting in light of recent evidence suggesting that entrepreneurs may enjoy a higher tolerance for risk than other non-entrepreneurial agents. ${ }^{6}$

The analytical expression for the first order condition that determines the optimal mix of $i_{s, t}$ and $i_{r, t}$ is detailed in the appendix. To provide a good understanding of the optimal choices implied by the constrained optimization in (13) Figure 1 provides some comparative statics of the sensitivity of the optimal ratio of risky to safe investment to variations in the degree of idiosyncratic risk $\sigma$ and the future price of capital $q_{t+1}$. In the left panel we can observe

\footnotetext{
${ }^{6}$ See Moskowitz and Vissing-Jørgensen (2002) for empirical evidence and Polkovnichenko (2003) for a theoretical interpretation of the evidence along the lines expressed here.
} 

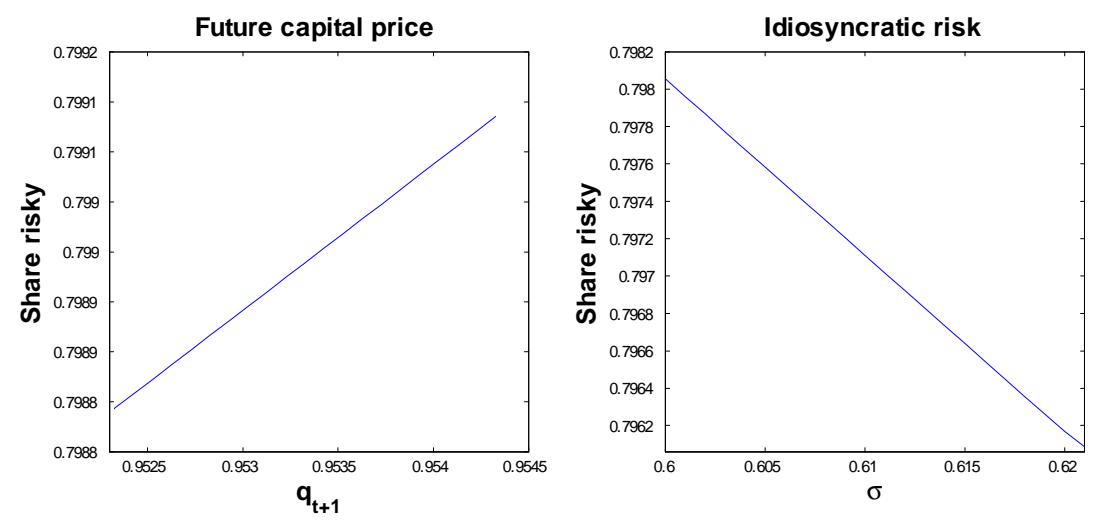

Figure 1: The share of risky investment as a function of the price of capital in period $t+1$, $q_{t+1}$, and the level of idiosyncratic risk $\sigma$.

that an increase in $q_{t+1}$ encourages more investment in the risky technology by decreasing the severity of future financing constraints. On the other hand, in the right panel we observe that an increase in idiosyncratic risk induces entrepreneurs to shift out of the risky project and into the safe alternative.

\section{General Equilibrium}

In this section we embed the entrepreneurial sector in a general equilibrium framework. Figure 2 contains an explanatory chart to aid in understanding the economic relationships between the different agents. Consider an infinite horizon discrete-time economy populated by three types of agents: households (measure 1), entrepreneurs (measure $\eta$ ) and firms (measure 1), and where within each type there is a continuum of agents. There are two types of goods: consumption goods and capital. Entrepreneurs produce capital using consumption goods and are subject to agency problems when seeking external finance. They finance their investment using their own net worth and external funds from households. Firms produce the consumption good using labor (from households and entrepreneurs) and capital, and are not subject to any agency problems. In order to better understand the sequence of events in this economy Table 1 summarizes what happens within each period.

We turn now to analyze households' and firms' decision problems, and to aggregate entrepreneurs' investment decisions to specify the behavior of the entrepreneurial sector.

\subsection{Households}

There is a continuum of risk-averse households who maximize expected lifetime utility of consumption, $c_{t}$, and leisure, $\left(1-l_{t}\right)$,

$$
E_{0} \sum_{t=0}^{\infty} \beta^{t} u\left(c_{t}, l_{t}\right)
$$

subject to a budget constraint given by

$$
c_{t}+q_{t} k_{t+1}=q_{t}(1-\delta) k_{t}+r_{t} k_{t}+w_{t} l_{t}
$$




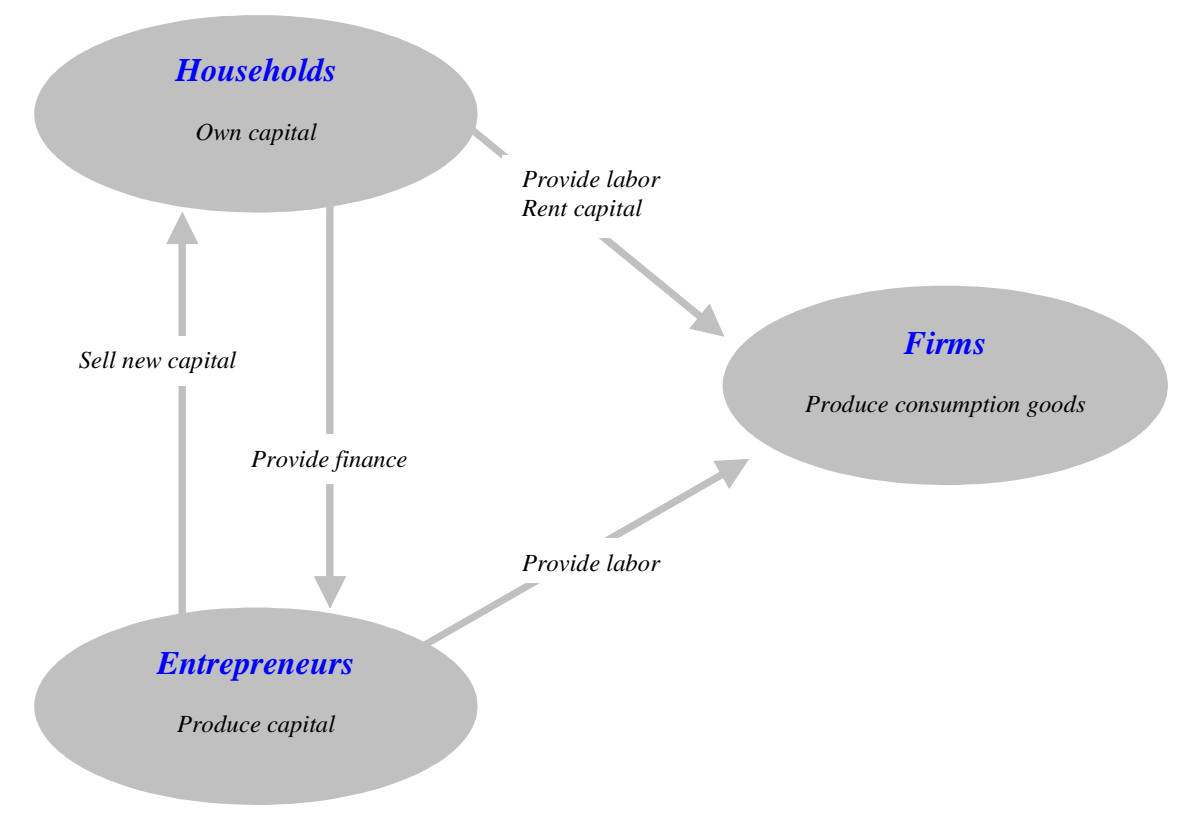

Figure 2: The economy - agents and their economic relationships

taking as given wages $w_{t}$, the price of capital $q_{t}$, and the equilibrium rate of return on capital $r_{t+1}$. Households' optimal labor-leisure choice is given by:

$$
\frac{-u_{l}(t)}{u_{c}(t)}=w_{t}
$$

where $u_{c}(t)$ and $u_{c}(t)$ are respectively the marginal utility of consumption and the marginal disutility of labor in period $t$, and their optimal savings and consumption choice is given by the Euler equation:

$$
u_{c}(t)=\beta E_{t}\left[u_{c}(t+1) \frac{q_{t+1}(1-\delta)+r_{t+1}}{q_{t}}\right] .
$$

All savings are invested in capital, and the total stock of capital is then rented by consumers to firms who use it for production the following period and pay in return an interest rate of $r_{t+1}$. Households also provide intra-period finance to entrepreneurs at a zero interest rate.

\section{$3.2 \quad$ Firms}

Firms produce the consumption good using a constant returns to scale production function:

$$
Y_{t}=\theta_{t} F\left(K_{t}, L_{t}, L_{t}^{e}\right)
$$

where $K_{t}$ is capital, $L_{t}$ is labor supplied by households, $L_{t}^{e}=L^{e}$ is labor supplied by entrepreneurial agents, which is constant, and $\theta_{t}$ is the total factor productivity. Aggregate quantities are denoted in capital letters. The only source of dynamics in the model is $\theta_{t}$ which is subject to exogenous shocks, as will be detailed later when we discuss calibration. 


\begin{tabular}{cl}
\hline \hline Sequence & Events \\
\hline 1 & The aggregate productivity shock, $\theta_{t}$, is realized. \\
2 & - Firms hire labor from households and entrepreneurs and rent capital from \\
& households. These inputs are used to produce the consumption good, $Y_{t}=$ \\
& $\theta_{t} F\left(K_{t}, L_{t}, L_{t}^{e}\right)$. \\
& - Households make their consumption and savings choice. Savings are used to \\
& purchase new capital from entrepreneurs. \\
& - Entrepreneurs borrow from households, and decide how to allocate their invest- \\
3 & ment into risky and safe projects. \\
4 & Entrepreneurial production takes place. Loans are repaid to households. \\
& Old entrepreneurs consume and die.
\end{tabular}

Table 1: Sequence of events within one period

Perfect competition in the factor markets implies the following factor prices:

$$
\begin{aligned}
r_{t} & =\theta_{t} F_{1}(t) \\
w_{t} & =\theta_{t} F_{2}(t) \\
w_{t}^{e} & =\theta_{t} F_{3}(t)
\end{aligned}
$$

\subsection{Entrepreneurs}

\subsubsection{Entrepreneurial safe investment and capital production}

Aggregation of entrepreneurs' investment and capital production has to take into account the different investment patterns of the three sub-types of entrepreneurs; young, old unconstrained and old constrained. Young entrepreneurs are all (ex-ante) identical and make the same investment choices. Old unconstrained entrepreneurs have different levels of net worth but all invest identically too, at the optimal investment scale. Old constrained entrepreneurs with different levels of net worth invest differently but aggregation is simplified by the fact that their optimal choices of $i_{s, t}$ and $i_{r, t}$ are linear in wealth.

The overlapping generations structure implies that half of the entrepreneurial population (the old) invests under the knowledge that it will not be investing again in the future, and hence has no concern for risk management given that in the context of this model the only reason to care about risk is that it may decrease expected profits in future periods. To deal with this unrealistic feature we will allow for the share of the old to be lower than one half and calibrated according to empirical evidence (calibration will be discussed in Section 4) and this will be determined by parameter $\phi \leq 0.5$ which will be a time invariant factor capturing the share of the entrepreneurial population made up by the old generation. This adjustment does not affect entrepreneurs' optimal choices, as this can be interpreted at the microeconomic level as a fraction $(1-2 \phi) /(1-\phi)$ of young agents dying (and foregoing all their wealth) before reaching old age. 
Aggregate supply of new capital will be given by

$$
\begin{aligned}
K_{t+1}-(1-\delta) K_{t}= & \eta(1-\phi)\left(j_{t} z_{e} i_{s, t}+j_{t} z_{s} i_{s, t}^{\alpha}\right) \\
& +\eta \phi \int_{n_{t+1}^{\min }}^{n_{t+1}^{*}}\left(j_{t} z_{e} i_{s, t}^{o c}\left(n_{t+1}\right)+j_{t} z_{s} i_{s, t}^{o c \alpha}\left(n_{t+1}\right)\right) f\left(n_{t+1}\right) d n_{t+1} \\
& +\eta \phi\left(\frac{n_{t}^{\max }-n_{t}^{*}}{n_{t}^{\max }-n_{t}^{\min }}\right)\left(j_{t} z_{e} i_{s, t}^{f b}+j_{t} z_{s} i_{s, t}^{f b \alpha}\right) .
\end{aligned}
$$

where the first, second and third terms in the right hand side capture the capital supply of young, old constrained, and old unconstrained entrepreneurs, respectively.

\subsubsection{Entrepreneurial risky investment and R\&D spillovers}

Entrepreneurs' R\&D activity generates spillovers on other entrepreneurs' capital-producing technologies. Aggregate $\mathrm{R} \& \mathrm{D}$, denoted $R_{t}$, is

$$
\begin{aligned}
R_{t}= & \eta(1-\phi) z_{r} i_{r, t}^{\alpha}+\eta \phi \int_{n_{t+1}^{\min }}^{n_{t+1}^{*}} z_{r} i_{r, t}^{o c \alpha}\left(n_{t+1}\right) f\left(n_{t+1}\right) d n_{t+1} \\
& +\eta \phi\left(\frac{n_{t}^{\max }-n_{t}^{*}}{n_{t}^{\max }-n_{t}^{\min }}\right) z_{r} i_{r, t}^{f b \alpha}
\end{aligned}
$$

Spillovers affect the productivity of the safe technology through a multiplicative factor such that output (in terms of capital goods) of an entrepreneur that invests $i_{s, t}$ is $j_{t} z_{s} i_{s, t}^{\alpha}+j_{t} z_{e} i_{s, t}$, where

$$
\log \left(j_{t}\right)=\rho_{j} \log \left(j_{t-1}\right)+h_{t-1}
$$

and

$$
h_{t}=\rho_{h} h_{t-1}+\kappa\left(R_{t-1}-R_{s s}\right) .
$$

The assumption made is that there is a level of aggregate $R \& D$ (the steady state level $R s s$ ) that needs to be maintained to keep the productivity of the capital-producing technology constant at $j=1$. Any variation above or below this level will affect $j_{t} .{ }^{7}$ What is behind this specification is the notion that there is a level of $R \& D$ necessary to deal with changes in the economic environment (such as changes in agents' preferences, exhaustion of certain natural resources or the development of new technologies) and keep the level of capital production constant. The formulation of spillovers according to the specification in (31) and (32) guarantees that a temporary variation in $R_{t}$ away from $R_{s s}$ is able to generate long-run effects which are larger than the short-run effects, as is consistent with the empirical evidence which will be discussed in more detail in the calibration section.

\footnotetext{
${ }^{7}$ Notice that R\&D performed in period $t$ will start having spillover effects in period $t+2$ when the entrepreneurs who produced it are no longer alive.
} 


\subsection{Remaining Market Clearing Conditions}

We deal now with the remaining aggregate equilibrium conditions. The market for household labor clears by equating firms' demand for labor given by (27) and households' supply given by (23). The market for new capital clears by equating demand from households in (22) and (24) and supply of new capital in (29).

\section{Calibration}

We calibrate the economy to reproduce basic features of the U.S economy on a quarterly basis. In addition the calibration is designed so the results are comparable with the existing quantitative studies on agency costs and business cycle fluctuations, such as Carlstrom and Fuerst (1997) and Bernanke, Gertler and Gilchrist (1999).

Concerning the calibration of preferences, the utility function for households is chosen to be iso-elastic of the form:

$$
u\left(c_{t}, l_{t}\right)=\frac{c_{t}^{1-\gamma}-1}{1-\gamma}+v_{l}\left(1-l_{t}\right),
$$

with $v_{l}$ chosen so that households work one-third of their available time in the steady state. The intertemporal preference rate is set at $\beta=0.99$, selected to deliver an average annual real interest rate of 3 percent, and the risk aversion parameter $\gamma$ is set at 2, although different values (between 1 and 4) are also tested for robustness.

The consumption good aggregate production technology is assumed to be Cobb-Douglas of the form:

$$
Y_{t}=\theta_{t} K_{t}^{\nu} L_{t}^{1-\nu-\nu^{e}} L_{t}^{\nu^{e}},
$$

with a capital share $\nu$ of 0.36 , a household labor share $\left(1-\nu-\nu^{e}\right)$ of 0.63 , and an entrepreneurial labor share $\nu^{e}$ of 0.01 . The share of entrepreneurial labor is positive to ensure that young entrepreneurs have positive net worth with probability one, and small so that the model dynamics closely resemble the standard RBC dynamics when the financial frictions in the model are removed. The capital depreciation rate is set to $\delta=0.025$ to match the capital/output ratio.

The technology shock, $\theta_{t}$, follows the process

$$
\log \theta_{t}=\rho \log \theta_{t-1}+\sigma_{\varrho} \varrho_{t}
$$

where $\sigma_{\varrho}=0.01, \rho=0.95$, and $\varrho_{t} \sim N(0,1)$. So far, all of these values are in line with those usually adopted in the business cycle literature (Cooley and Prescott (1995)).

The calibration of parameters concerning the entrepreneurial sector can be divided into three categories: those that control entrepreneurs' financing constraints, those that affect their investment opportunities, and those that determine the extent to which their R\&D activity has positive spillover effects on other firms.

The model does not explicitly address whether external finance for entrepreneurs takes the form of debt or equity, although the fixed-repayment contract strongly resembles debt. We will consider $n_{t}$, the wealth of entrepreneurs, to be the combination of retained earnings and 
inside equity, and $b_{t}$ to be debt and the only source of external finance, on the basis of the following argument: in small and medium enterprises a much larger share of equity-holders can be considered insiders, because (i) managers are more likely to own a larger share of the company, (ii) the prevalence of sponsor backed equity will be larger, and (iii) any equity-holder is bound to be closer to management than in a large publicly quoted firm in which arms-length share ownership is more prevalent. On top of this a large literature on R\&D financing has documented that $R \& D$ is primarily financed by retained earnings and equity rather than debt (Himmelberg and Petersen (1994), Aghion, Bond, Klemm, and Marinescu (2004)), so our calibration of the debt-to-assets ratio will reflect this. The parameter affecting financing constraints, $z_{e}$, is set to target a mean debt to assets ratio of $15 \%$ based on Himmelberg and Petersen (1994), who document a $6 \%$ average ratio for R\&D-intensive firms, and on the average debt to assets ratio for Compustat publicly listed firms, which is $25 \%$ according to Bates, Kahle, and Stulz (2009).

The entrepreneurial technology parameters are calibrated as follows. The capital share $\alpha$ is set to 0.22 (with values between 0.20 and 0.25 also tested for robustness), reflecting, on the one hand, the observation in Valentinyi and Herrendorf (2008) that the capital share in investment good producing sectors is lower (0.28) than the one in consumption good production (0.35), and, on the other hand, taking into account that $i_{s, t}$ and $i_{r, t}$ represent variable capital and that there may be some additional fixed factor of production (say each entrepreneur owns some real estate that it may flexibly employ for his entrepreneurial venture) which consumes part of the income share considered to accrue to capital and which is not specifically modeled.

The productivity factor for the safe and risky technologies, $z_{s}$ and $z_{r}$, and the idiosyncratic risk of the risky technology, $\sigma$, are set to match a return to the safe technology of $3 \%$, a Sharpe ratio for the risky technology close to 2.5 , and a share of R\&D investment over GDP of $1.5 \%$, in the low end of the estimates for developed countries (OECD, 2007).

The share of entrepreneurs $\eta$ is set to match the documented size of the private (i.e. not listed in a stock exchange) sector in the U.S. economy, which roughly accounts for half of employment and investment. The share of the entrepreneurial population made up of old entrepreneurs, $\phi$, is set at $\phi=0.011$, a very low value that ensures that the unrealistic feature of old agents that are certain to terminate their entrepreneurial operations after the current period does not influence the dynamics.

Finally, the spillover parameters are calibrated to match the estimated long-run output elasticity of intra-industry R\&D documented in Bernstein and Nadiri (1989). They estimate the reduction in variable and average costs arising from $R \& D$ spillovers at the short and long runs for a range of industries and find an R\&D spillover elasticity of average costs of $0.1 \%(0.15 \%)$ in the short-run (long-run). To map these observations into our model, we calibrate $\kappa, \rho_{h}$, and $\rho_{j}$ such that a $1 \%$ increase in R\&D spillovers (captured by aggregate R\&D output) generates on average a reduction in the one-quarter ahead average cost of $0.1 \%$, and a reduction in the 10 -quarter ahead average cost of $0.15 \%$. 


\section{The Financial Accelerator and the Composition of Investment}

In this section we report the qualitative and quantitative findings concerning aggregate investment and output dynamics. The model is simulated by calculating a second order approximation of the equilibrium conditions around the deterministic steady state and solving the resulting system of difference equations. We study in section 5.1 the model's implications for the behavior of the composition of aggregate entrepreneurial investment over the business cycle. In section 5.2 we examine the role of this novel transmission mechanism in amplifying and propagating aggregate productivity shocks.

\subsection{The Composition of Investment across the Business Cycle}

The cyclical dynamics of the composition of firms' investment are at the heart of the amplification mechanism we describe in this paper. To better understand the mechanisms underlying these dynamics, we simulate and compare the dynamics of the model described so far in this paper, which we will label the Precautionary model, with one in which there are no financial frictions in the entrepreneurial sector, which we will label from now on the $R B C$ version, and which corresponds to the frictionless investment behavior of entrepreneurs described in subsection 2.2. ${ }^{8}$ The calibration of the $R B C$ model and the Precautionary model is the same, which results in different steady state values for both economies. For this reason, we study the dynamics as percent deviations from steady state values.

Figure 3 plots the impulse response functions of selected variables to a negative $1 \%$ shock to the productivity of the consumption good producing firms. ${ }^{9}$ In the $R B C$ version, following the shock, firms' demand for new capital produced by entrepreneurs falls, which results in a fall in its price. This fall in the price of capital influences entrepreneurs' investment choices: investing in the capital-producing safe technology is now relatively less profitable compared to investing in the risky technology, so there is a shift in the share of resources allocated by entrepreneurs towards the risky activity (the opportunity cost effect). This shift is caused by a decrease in investment in the safe technology only, as the level of investment in the risky activity remains unchanged. ${ }^{10}$ The $R B C$ version of the model thus delivers cyclical patterns that follow a Schumpeterian view in which recessions are periods when firms carry out structural changes to correct for inefficiencies in the organization or to redirect their strategy by innovating or investing in new products or markets.

In the Precautionary model, however, the presence of financing constraints alters the dynamics following the shock. As before, following the negative productivity shock and the decrease in demand for new capital, the price of capital decreases and this introduces again an incentive for

\footnotetext{
${ }^{8}$ Calling it "RBC", for "Real Business Cycle", is a slight abuse of the term as there are two differences with respect to the standard $\mathrm{RBC}$ framework. On the one hand, in the standard framework capital is produced using consumption goods by means of a one-to-one technology while in my version there is a capital producing sector with decreasing returns to scale. On the other hand, part of the wage bill of firms reverts to entrepreneurs, which is not the case either in the standard framework.

${ }^{9}$ The shock does not affect the productivity of the entrepreneurs' safe capital-producing technology or of their risky $\mathrm{R} \& \mathrm{D}$ technology.

${ }^{10}$ The level of investment in the risky activity remains unchanged in the RBC version because both its return and the opportunity cost of capital invested in $\mathrm{R} \& \mathrm{D}$ (which in the unconstrained model is storage) remain constant and are not affected by the business cycle.
} 

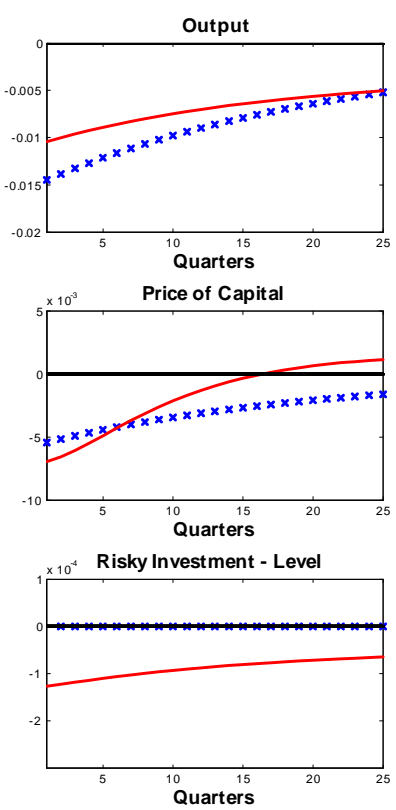
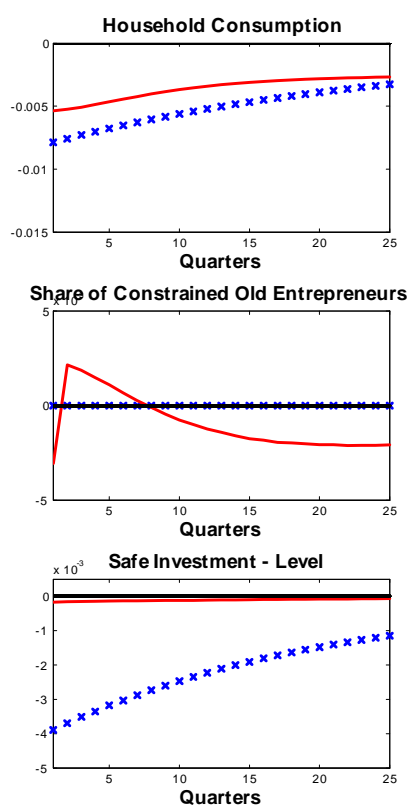
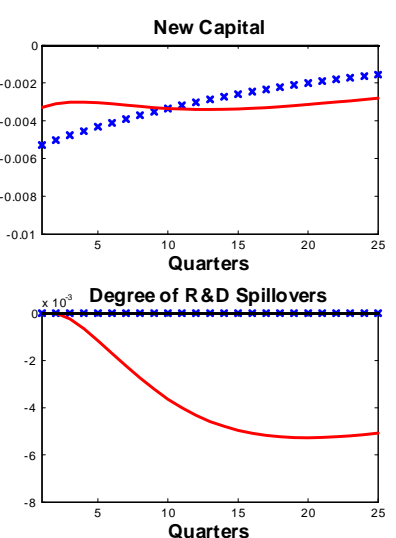

Share of Risky Entrepreneurial Investment

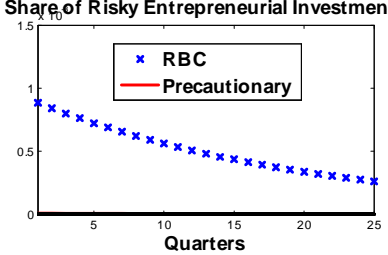

Figure 3: Impulse response functions to a $1 \%$ negative shock to aggregate productivity of the consumption-good producing firms in both the $R B C$ and Precautionary models. The responses are percentage deviations of a variable from its steady-state value.

entrepreneurs to shift production away from the safe capital-producing technology towards risky R\&D. This, however, increases the severity of credit constraints, for three reasons. First, there is now an incentive to produce more using the less pledgeable technology. Entrepreneurs can only borrow against part of the returns of the safe capital-producing technology, but R\&D has to be funded entirely by internal resources. Secondly, the value of collateral (capital), which is driven by $q_{t}$, decreases. And finally wealth available to newborn entrepreneurs, $n_{t}$, is lower because the wages they are paid by firms decrease. Young firms anticipate that given the persistence of the productivity shock this means that the probability of facing financing constraints in their second period has increased. This indeed the case, as is shown in the central panel of Figure 3 where the share of credit constrained old entrepreneurs increases sharply in the second quarter following the shock, and stays high for 4 or 5 quarters. This calls for a decrease in investment in the risky $R \& D$ technology to alleviate future financing problems. In sum, the introduction of financing constraints means that the Schumpeterian drive to shift production towards $R \& D$ in downturns is met with an opposing force that pushes towards a decrease in R\&D investment to alleviate the probability of facing future credit constraints. In the benchmark calibration of Figure 3 the Schumpeterian effect dominates but the procyclicality of R\&D is significantly smaller than that of the $R B C$ version, and, in fact, as the lower-right panel of Figure 3 shows, is essentially acyclical.

The negative impact of the decrease in R\&D investment reaches its maximum in the medium to long-run, at around 15 quarters following the initial shock. As a result of this effect, the productivity of the capital-producing technology decreases sharply, which itself has several implications. First, the supply of new capital contracts, showing up as an increase in the price of 


\begin{tabular}{lccc}
\hline \hline & Data & $R B C$ & Precautionary \\
\hline Share R\&D over GDP & $1.5 \%-3 \%$ & $40.3 \%$ & $1.4 \%$ \\
corr (R\&D growth,GDP growth) & $0.100-0.490(1)$ & 0.000 & 0.993 \\
corr (share R\&D,GDP) & $-0.004(2)$ & -0.171 & -0.164 \\
corr (R\&D,Safe Investment) & $0.214(2)$ & 0.000 & 0.959 \\
\hline
\end{tabular}

Table 2: Cyclical Behavior of the Composition of Entrepreneurial Investment - (1) Obtained from Walde and Woitek (2004). (2) Obtained from Aghion, Askenazy, Berman, Cette and Eymard (2008).

capital. On the other hand, the share of credit constrained entrepreneurs falls below the steady state value; this is mostly due to the fact that investment opportunities for entrepreneurs are not so attractive which means that the investment requirements associated to the optimal scale are lower.

Table 2 displays some second moments of the simulated data and compares them to those in the empirical literature. The safe investment is identified with fixed capital formation, and the risky investment with research and development expenditures. Evidence on the cyclical pattern of aggregate R\&D investment is contained in Barlevy (2007) who uses aggregate and firm-level data to confirm that R\&D growth rates correlate positively with GDP growth rates in the US, as had been found in numerous previous studies. The simulated series in the $R B C$ model yields no correlation as the level of $\mathrm{R} \& \mathrm{D}$ investment is constant. The Precautionary model yields a near perfect positive correlation; this is due to the fact that credit constrained firms will have more wealth and better access to finance and invest more in every item, so levels of all types of investment are expected to be positively and highly correlated with GDP.

Empirical evidence on the cyclical behavior of the aggregate composition of investment is harder to find, and to the best of my knowledge there is no study of how the ratio of $\mathrm{R} \& \mathrm{D}$ to total investment (physical investment plus $\mathrm{R} \& \mathrm{D}$ ) fluctuates around the business cycle. The closest empirical counterpart can be found in firm-level studies that relate R\&D-to-totalinvestment ratios to GDP or sales, and the patterns found for these firms may provide a useful and relatively accurate insight into the behavior of the aggregate composition of investment to the extent that the sample is large enough and representative of the $R \& D$ producing population of firms. One such study is Aghion, Askenazy, Berman, Cette and Eymard (2007), who use a large sample of French firms to study the behavior of the ratio of R\&D-to-total investment. They find that such ratio is acyclical on average, and turns procyclical for the most credit constrained firms. In the $R B C$ version, that ratio is countercyclical, with a correlation between the ratio of $R \& D$ to total investment and GDP growth of -0.171 , whereas that same correlation is slightly lower in the Precautionary model. Finally, the relationship between physical investment and R\&D investment is positive in their sample, and so it is in the simulated data using the Precautionary model. The $R B C$ version again delivers a zero correlation given that $\mathrm{R} \& \mathrm{D}$ investment is constant.

Putting everything together, the Precautionary model is able to deliver both a positive correlation between output growth and $R \& D$ growth and a negative but small correlation between 


\begin{tabular}{lcccccc}
\hline \hline Model & $\sigma_{Y} \%$ & $\sigma_{C} \%$ & $\sigma_{I} \%$ & $\frac{\sigma_{I}}{\sigma_{Y}}$ & $\frac{\sigma_{Y}}{\sigma_{\text {tech }}}$ & $\frac{\sigma_{I}}{\sigma_{\text {tech }}}$ \\
\hline RBC & $1.30 \%$ & $0.95 \%$ & $0.98 \%$ & 0.75 & 0.99 & 0.75 \\
Precautionary & $1.29 \%$ & $0.91 \%$ & $1.44 \%$ & 1.12 & 0.99 & 1.11 \\
Data & $1.36 \%$ & 0.94 & 4.87 & 5.39 & - & - \\
Cordoba and Ripoll (2004) & - & - & - & - & 1.47 & - \\
\hline
\end{tabular}

Table 3: Summary of Numerical Results - Comparison of Outcomes (Real U.S. data for 19852005 from Bachmann, et al (2008)). Simulated data is HP filtered (lambda=1,600)

output growth and the ratio of risky-to-total investment, as in the data, a combination of results which the $R B C$ model is unable to produce. This result is despite the fact that we are comparing real data, subject to multiple demand and supply shocks, with simulated data whose only source of dynamics is a technology shock, which greatly simplifies the dynamics of business cycles and may exaggerate correlations.

\subsection{Amplification and Propagation of Productivity Shocks}

We now turn to study how the mechanism described in this paper affects the reaction of aggregate investment and output to technology shocks, both contemporaneously (amplification vs. dampening) and through time (propagation). We will again be comparing the frictionless $R B C$ version of the model with the full Precautionary version.

Inspecting Figure 3 we can see that the $R B C$ version of the model produces a reaction of output and investment that closely tracks the evolution of the technology shock, as is well known. In essence, there is little amplification or propagation in this version. In the Precautionary version, however, the contemporaneous reaction of output is around $30 \%$ smaller than in the $R B C$ model, so there is dampening in the short run, but the long term propagation of the shock is larger. The intuition for this result is that, following the impact of the negative technology shock, young entrepreneurs, anticipating the higher probability of facing financing constraints in the following period, are reluctant to implement a large shift towards the R\&D technology, as the volatility of its cash flows increases the probability of future financing problems. This means that, relative to the unconstrained $R B C$ case, entrepreneurs do not decrease their investment in the safe capital-producing technology as much and the supply of new capital does not contract significantly. This results in a smaller decrease in the aggregate stock of capital in the Precautionary model, and a smaller contemporaneous amplification of the shock.

The other implication of this behavior is that investment in R\&D falls more in the Precautionary model. The aggregate effects of this occur further in the future through the technological spillovers that aggregate R\&D produces on entrepreneurs' capital-producing technology, which, as Figure 3 shows, accumulate through time and are very persistent. In the benchmark calibration, spillover effects are large enough to cancel the dampening effect around 25 quarters after the impact of the shock, and subsequently are large enough to generate higher propagation than in the $R B C$ version. In summary, the combination of financing frictions and investment choice introduces a trade-off between short-run amplification and long-run propagation. The stronger 
the contemporaneous dampening of shocks, the larger the intertemporal propagation.

It is worth mentioning at this point that the way financing frictions are introduced in this model is such that their ability to alter dynamics is limited. This is so because by assumption only entrepreneurs face credit constraints, and their role in this economy is to produce capital to be used by consumption good producing firms. The stock of capital depreciates slowly (at a rate of around 2,5\% quarterly), so if financing frictions only affect the supply of new capital that replaces the depreciated one their impact on dynamics cannot be too large. If financing frictions had been modeled such that they affected the production of total output effects could possibly be much larger. ${ }^{11}$

Table 3 presents some second moments of the $R B C$ and Precautionary models and compares them to the empirical data. Despite the contemporaneous dampening effect of entrepreneurs' precautionary behavior, intertemporal propagation acts to increase the volatility of output to the point that the standard deviation of output in the Precautionary model is lower but close to that of the $R B C$ model, and the same happens for households' consumption. Intertemporal spillovers effects end up making households' investment more volatile in the Precautionary model despite the fact that on impact the shock affects investment less in that model.

A benchmark against which to compare our results is the study of Cordoba and Ripoll (2004), who question the quantitative significance of collateral constraints to significantly amplify the effects of technology shocks on aggregate investment. They obtain a degree of amplification, measured as the standard deviation of output relative to the standard deviation of the total factor productivity process, of 1.47, above the 0.99 obtained for both the Precautionary and $R B C$ versions. Our result thus lends more support to the notion that collateral constraints may not be able to generate a significant amplification of productivity shocks. Indeed, as this analysis suggests, they may significantly dampen their short-run effects.

\section{Robustness of the Results on Amplification and Propagation}

In this section we explore the sensitivity of results to variations in the parameter values used in the baseline calibration. In particular, the effects of changes in the capital share, the degree of R\&D spillovers, and the amount of entrepreneurial idiosyncratic risk will be studied.

\subsection{Idiosyncratic Risk}

The volatility of the returns to the risky entrepreneurial activity, which is entirely idiosyncratic, is a key element of the precautionary behavior of young entrepreneurs who anticipate the possibility of being credit constrained when old. As a result, varying the degree of entrepreneurial risk has important consequences. We simulate the response to a negative $1 \%$ aggregate productivity shock for two parameterizations of this risk. A low degree of risk, corresponding to $\sigma=0.5$ and a Sharpe ratio of 9.5 and a high one corresponding to $\sigma=0.62$ and a Sharpe ratio of 1 .

\footnotetext{
${ }^{11}$ For a detailed analysis of the difference between modeling financing constraints in the capital producing sector or in the consumption good sector see Carlstrom and Fuerst (1998).
} 

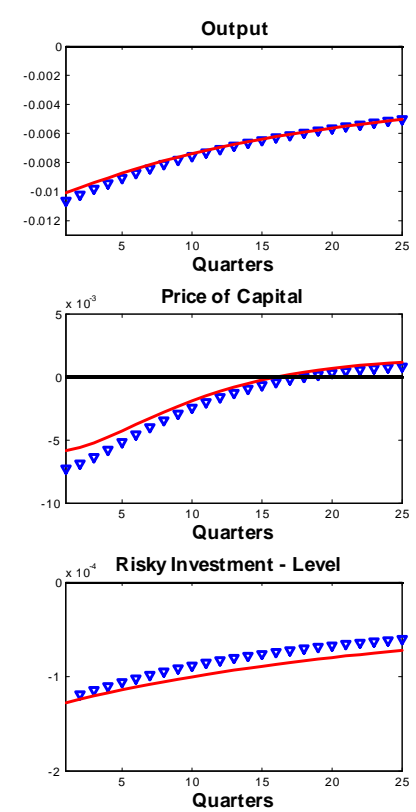
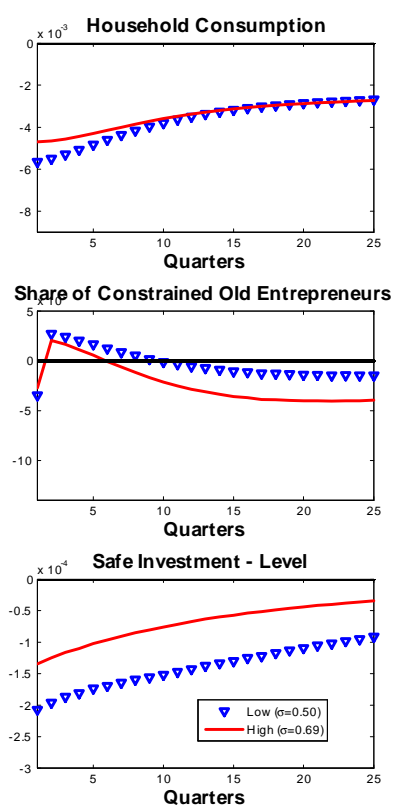
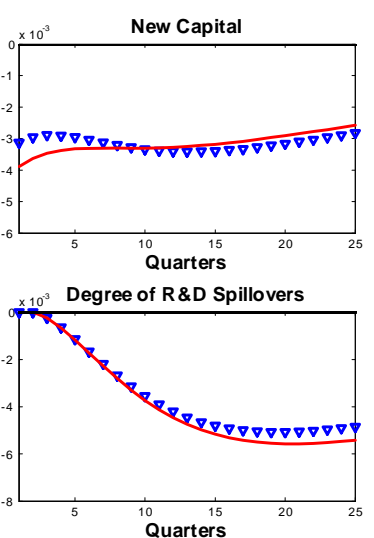

Sharefof Risky Entrepreneurial Investment

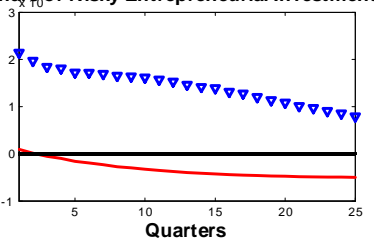

Figure 4: Impulse response functions to a $1 \%$ negative shock to aggregate productivity of the consumption-good producing firms for different degrees of idiosyncratic risk. The responses are percentage deviations of a variable from its steady-state value.

In the benchmark calibration the net effect of the two opposing forces that determine whether the share of risky investment is procyclical or countercyclical is such that the Schumpeterian rate-of-return effect dominates and the ratio is procyclical. If we increase idiosyncratic risk slightly to $\sigma=0.62$ from the benchmark value of $\sigma=0.60$ the effect is quite dramatic and such that the net effect is close to acyclicality. Further increases in the calibration of idiosyncratic risk bring the Sharpe ratio close to zero, which is empirically not realistic.

The amount of new capital produced and sold to consumers falls more with higher risk, however, despite the fact that young entrepreneurs do not cut their supply as much. The reason for this lies in the fact that demand for new capital falls more (consumption falls less), and the cut in capital supply come mostly from the old generation, for which the rate-of-return effect is strongest.

\subsection{Capital Share}

As was mentioned above, the way financial frictions are introduced in this economy affects their potential to influence aggregate dynamics. Given that they only affect the production of capital goods and that the stock of capital depreciates slowly, this limits their effect. On top of this, the share of capital as a factor of production is around one third, which further limits the effects. So it seems reasonable to suspect that the strength of the effects may depend on two parameters; $\delta$, the rate of depreciation of capital, and $\alpha$, the capital share in production of consumption goods. While estimates for $\delta$ do not vary much and stand at around 2,5\% quarterly, estimates for $\alpha$ vary from around 0.20 to 0.40 from country to country according to recent evidence in 

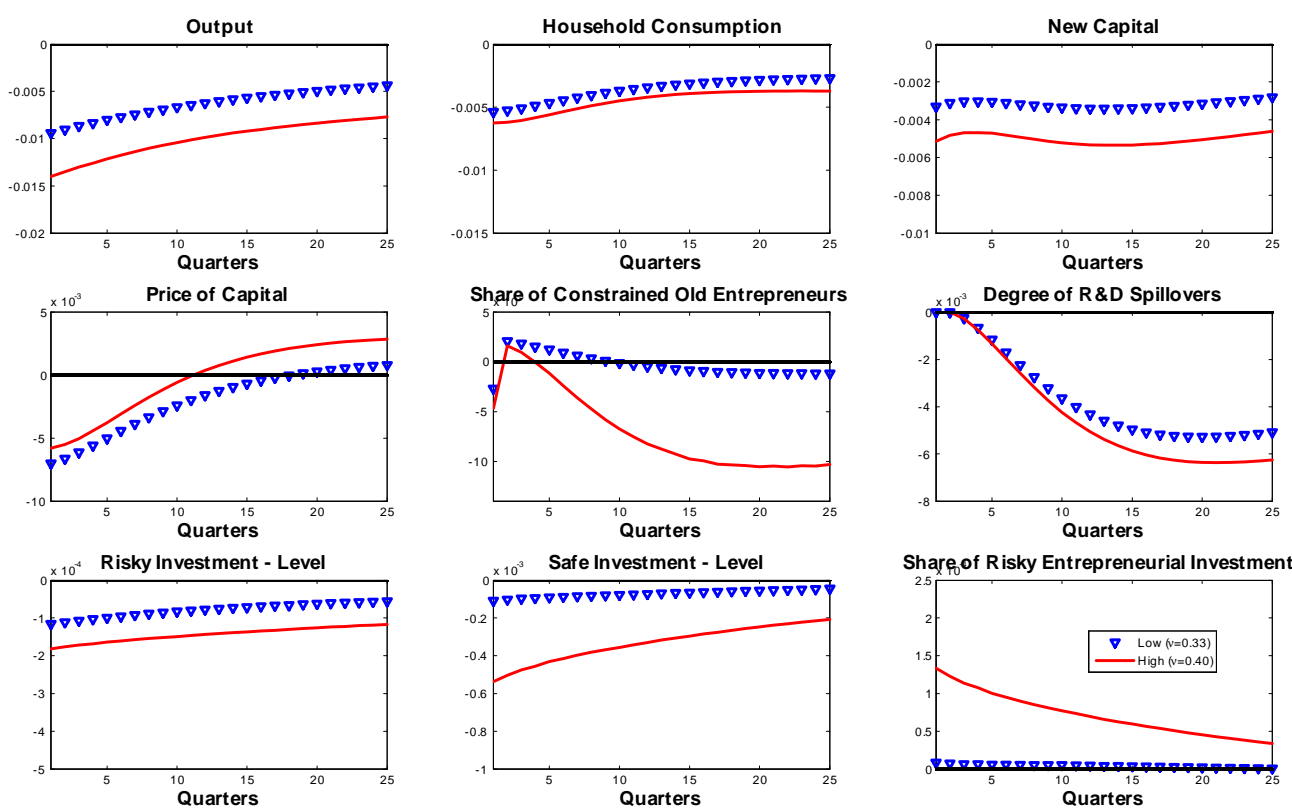

Figure 5: Impulse response functions to a $1 \%$ negative shock to aggregate productivity of the consumption-good producing firms for different capital shares. The responses are percentage deviations of a variable from its steady-state value.

Gollin (2002). ${ }^{12}$ Figure 5 shows the impulse responses to a negative $1 \%$ productivity shock for the Precautionary model calibrated at two values of the capital share, $\nu=0.33$ and $\nu=0.40$.

Amplification in the model is greater for larger values of the capital share, and the reaction of many variables resembles that of the $R B C$ model version. The intuition for this result lies in the fact that by increasing the capital share and maintaining the size of the entrepreneurial population and of its production opportunities, this exercise alleviates financing constraints and decreases sharply the share of old constrained entrepreneurs. Financing constraints are less of a concern with higher capital shares, and that is reflecting in weaker precautionary mechanism that delivers less dampening.

\subsection{Degree of Spillovers}

The medium and long-run effects of short-run changes in the composition of investment are channeled through the R\&D spillovers. Figure 6 plots the impulse response of the degree of spillovers, the composition of entrepreneurial investment, and output following a negative $1 \%$ consumption-good production productivity shock for three levels of spillovers, starting at no spillover effects at all $(\kappa=0)$, up to spillovers $(\kappa=30)$ that imply contemporaneous and longrun elasticities of output to aggregate $\mathrm{R} \& \mathrm{D}$ investment of 0.26 and 0.40 respectively, on the upper part of the empirical estimates.

Two effects of the degree of spillovers are notable. On the one hand, the long run effect

\footnotetext{
${ }^{12}$ Higher values for the capital share may be warranted as well for another reason: intangible capital is not fully accounted for in national accounts and hence capital's income share might be larger than 0.35. See Antunes and Cavalcanti (2007).
} 

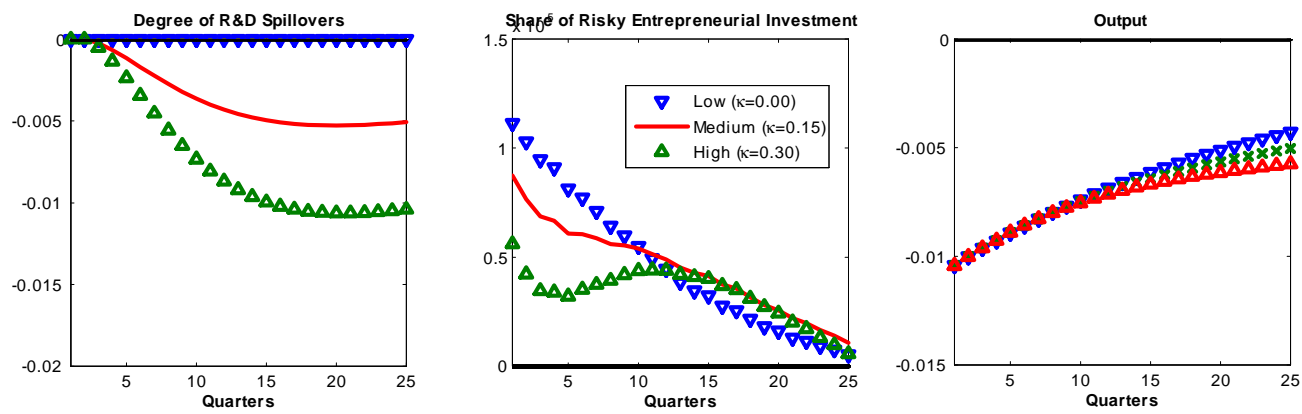

Figure 6: Impulse response functions to a $1 \%$ negative shock to aggregate productivity of the consumption-good producing firms for different degrees of $R \& D$ spillovers. The responses are percentage deviations of a variable from its steady-state value.

of higher spillovers is as expected; larger spillovers deliver more intertemporal propagation of shocks, and the differential effect of spillovers (or the gap between the output reaction with no spillovers and the output reaction with spillovers) keeps growing even after 25 quarters following the occurrence of the shock.

Perhaps less obvious are the short run effects. The contemporaneous reaction of the share of risky investment is much less procyclical the higher the spillovers, and then increases after around five quarters in such a way that after 10 quarters the degree of spillovers does not significantly affect the composition of investment. One likely explanation is that households, in anticipation of very negative spillovers that will make producing capital highly unproductive (and hence cut the supply and increase its price), bring capital purchases forward and do not decrease demand for capital much following a negative shock. After several periods, the negative spillovers start making the safe investment less desirable to entrepreneurs relative to the risky one and they shift production towards a higher share of risky investment. 


\section{Conclusion}

This paper introduces a model in which risk-neutral entrepreneurs behave in a risk averse manner and in which the source of risk aversion has to do with investment opportunities and financial constraints. The model also provides a theoretical underpinning for the countercyclicality of financing constraints. We then use this framework to explore the implications of firms' riskaverse behavior for the role of credit market imperfections in amplifying or dampening shocks to the macroeconomy. A novel dampening mechanism of macroeconomic shocks is identified, which is based on a time-varying likelihood of future financing constraints that affects firms' preference for the risk profile of their portfolio of investment projects. The dampening effect is shown to be quantitatively large. On the other hand, this framework is able to account for the empirically documented cyclical variation in the composition of real investment, a feature which the existing models studying the macroeconomic implications of financial constraints cannot account for.

A next step in this research agenda is to study if this mechanism can be potentially enhanced by financial intermediaries' own credit constraints, creating a feedback mechanism between entrepreneurial investment choices, asset prices, and banks' balance sheet conditions and risk-sharing capacity. A main source of risk and liquidity management for firms are financial intermediaries, both using ex-ante protection through credit lines, and ex-post protection by borrowing on the spot market. The ability of financial intermediaries and capital markets to satisfy firms' liquidity demand may itself be subject to similar countercyclical constraints as non-financial firms, creating the potential for a two-way response between firms' investment decisions and intermediaries' liquidity supply. This feedback effect could be important and is left for future research. 


\section{Appendix}

\subsection{Entrepreneurs' Problem - First Order Conditions}

The first order condition that solves the entrepreneurs' optimization problem defined in (13) and (20) is:

$$
\begin{aligned}
0= & E_{t}\left[\frac{-\left(\frac{d n_{t+1}^{\max }}{d i_{s, t}}-\frac{d n_{t+1}^{\min }}{d i_{s, t}}\right)}{\left(n_{t+1}^{\max }-n_{t+1}^{\min }\right)^{2}}\right] \Omega_{t+1}+E_{t}\left\{\frac{1}{n_{t+1}^{\max }-n_{t+1}^{\min }}\left[\frac{d n_{t+1}^{\max }}{d i_{s, t}}\left(\psi_{t+1}+\frac{n_{t+1}^{*}}{2}\right)\right]\right\} \\
& E_{t}\left\{\frac{1}{n_{t+1}^{\max }-n_{t+1}^{\min }}\left[\left(n_{t+1}^{\max }-\frac{n_{t+1}^{*}}{2}\right)-\tau_{t+1} n_{t+1}^{\min \alpha} \frac{d n_{t+1}^{\min }}{d i_{s, t}}\right]\right\}
\end{aligned}
$$

where

$$
\begin{gathered}
\Omega_{t+1}=\left(n_{t+1}^{\max }-n_{t+1}^{*}\right)\left(\psi_{t+1}+\frac{n_{t+1}^{*}}{2}\right) \\
+\left(n_{t+1}^{\max }-n_{t+1}^{\min }\right) \frac{n_{t+1}^{\max }}{2}+\frac{\tau_{t+1}}{1+\alpha}\left(n_{t+1}^{*(1+\alpha)}-n_{t+1}^{\min (1+\alpha)}\right) \\
\psi_{t+1}=q_{t+1} z_{s} i_{s, t+1}^{f b \alpha}+q_{t} z_{e} i_{s, t+1}^{f b}+z_{r} i_{r, t+1}^{f b \alpha}-i_{s, t+1}^{f b}-i_{r, t+1}^{f b}, \\
\lambda_{t}=\frac{\left[z_{r}\left(1-j_{t} q_{t} z_{e}\right)\right]^{\frac{1}{\alpha-1}}}{\left(q_{t} j_{t} z_{s}\right)^{\frac{1}{\alpha-1}}+z_{r}^{\frac{1}{\alpha-1}}\left(1-q_{t} j_{t} z_{e}\right)^{\frac{\alpha}{\alpha-1}}}
\end{gathered}
$$

and

$$
\chi_{t}=1-\left(1-q_{t} j_{t} z_{e}\right) \lambda_{t} .
$$

To obtain the optimal solution expression (33) needs to be solved for $i_{s, t}$. The amount of risky investment, $i_{r, t}$, can then be obtained from:

$$
i_{r, t}=w_{t}^{e}-\left(1-q_{t} j_{t} z_{e}\right) i_{s, t} .
$$

\subsection{Aggregate Equilibrium Conditions and Solution Method}

The remaining equilibrium conditions are:

$$
\begin{gathered}
q_{t} C_{t}^{-\gamma}=\beta E_{t}\left[C_{t+1}^{-\gamma}\left(\nu \theta_{t+1} K_{t+1}^{\nu-1} L^{1-\nu-\nu^{e}}+q_{t+1}(1-\delta)\right)\right] \\
\theta_{t} K_{t}^{\nu} L^{1-\nu-\nu^{e}}=C_{t}+q_{t}\left(K_{t+1}-(1-\delta) K_{t}\right) \\
\eta w_{t}^{e}=\nu^{e} \theta_{t} K_{t}^{\nu} L^{1-\nu-\nu^{e}}
\end{gathered}
$$




$$
\begin{aligned}
& K_{t+1}-(1-\delta) K_{t}=\eta(1-\phi)\left(j_{t} z_{e} i_{s, t}+j_{t} z_{s} i_{s, t}^{\alpha}\right) \\
& +\eta \phi \int_{n_{t+1}^{\min }}^{n_{t+1}^{*}}\left(j_{t} z_{e} i_{s, t}^{o c}\left(n_{t+1}\right)+j_{t} z_{s} i_{s, t}^{o c \alpha}\left(n_{t+1}\right)\right) f\left(n_{t+1}\right) d n_{t+1} \\
& +\eta \phi\left(\frac{n_{t}^{\max }-n_{t}^{*}}{n_{t}^{\max }-n_{t}^{\min }}\right)\left(j_{t} z_{e} i_{s, t}^{f b}+j_{t} z_{s} i_{s, t}^{f b \alpha}\right), \\
& R_{t}=\eta(1-\phi) z_{r} i_{r, t}^{\alpha}+\eta \phi \int_{n_{t+1}^{\min }}^{n_{t+1}^{*}} z_{r} i_{r, t}^{o c \alpha}\left(n_{t+1}\right) f\left(n_{t+1}\right) d n_{t+1} \\
& +\eta \phi\left(\frac{n_{t}^{\max }-n_{t}^{*}}{n_{t}^{\max }-n_{t}^{\min }}\right) z_{r} i_{r, t}^{f b \alpha} \\
& \log \left(j_{t}\right)=\rho_{j} \log \left(j_{t-1}\right)+h_{t-1}, \\
& h_{t}=\rho_{h} h_{t-1}+\kappa\left(R_{t-1}-R_{s s}\right), \\
& n_{t+1}^{\max }=q_{t} j_{t} z_{s} i_{s, t}^{\alpha}+(1+\sigma) z_{r}\left[n_{t}-\left(1-q_{t} j_{t} z_{e}\right) i_{s, t}\right]^{\alpha}, \\
& n_{t+1}^{\min }=q_{t} j_{t} z_{s} i_{s, t}^{\alpha}+(1-\sigma) z_{r}\left[n_{t}-\left(1-q_{t} j_{t} z_{e}\right) i_{s, t}\right]^{\alpha}, \\
& n_{t}^{*}=\left(\frac{\alpha q_{t} j_{t} z_{s}}{1-q_{t} j_{t} z_{e}}\right)^{\frac{1}{1-\alpha}}+\left(\alpha z_{r}\right)^{\frac{1}{1-\alpha}}-q_{t} j_{t} z_{e}\left(\frac{\alpha q_{t} j_{t} z_{s}}{1-q_{t} j_{t} z_{e}}\right)^{\frac{1}{1-\alpha}} \\
& i_{s, t}^{f b}=\left(\frac{\alpha q_{t} j_{t} z_{s}}{1-q_{t} j_{t} z_{e}}\right)^{\frac{1}{1-\alpha}}, \\
& i_{r, t}^{f b}=\left(\alpha z_{r}\right)^{\frac{1}{1-\alpha}}, \\
& i_{s, t}^{o c}=\lambda_{t} n_{t}
\end{aligned}
$$

and

$$
i_{r, t}^{o c}=\chi_{t} n_{t}
$$

For the purposes of the dynamic analysis the household labor supply has been fixed at 0.3, to focus attention at the mechanisms introduced in this paper. In the equilibrium conditions described here $L_{t}=L=0.3$.

To solve the model we calculate the optimal policy rules for $q_{t}, C_{t}, K_{t+1}, w_{t}^{e}, n_{t+1}^{\max }, n_{t+1}^{\min }, n_{t}^{*}$, $i_{s, t}, i_{r, t}, i_{s, t}^{f b}, i_{r, t}^{f b}, i_{s, t}^{o c}, i_{r, t}^{o c}, R_{t}, j_{t}$, and $h_{t}$ from (33), (38) and (39)-(52) as a function of exogenous state variable $\theta_{t}$ and endogenous state variables $, K_{t}, n_{t}^{\max }, n_{t}^{\min }, j_{t-1}$, and $h_{t-1}$, where the law of motion for $\theta_{t}$ is given by:

$$
\log \theta_{t}=\rho \log \theta_{t-1}+\sigma_{\varrho} \varrho_{t},
$$

and $\varrho_{t+1} \sim N(0,1)$.

The model is simulated using Dynare by calculating a second order approximation of the equilibrium conditions around the deterministic steady state and solving the resulting system of difference equations. 


\section{References}

[1] Acemoglu, Daron and Fabrizio Zilibotti. 1997. "Was Prometheus Unbound by Chance? Risk, Diversification, and Growth," Journal of Political Economy, vol. 105(4): 709-51.

[2] Aghion, Philippe, Angeletos, G.-M., Banerjee, A., and Manova, K. 2010. "Volatility and Growth: Credit Constraints and Productivity-Enhancing Investment"; Journal of Monetary Economics, 57: 246-65.

[3] Aghion, Philippe, Philippe Askenazy, Nicolas Berman, Gilbert Cette and Laurent Eymard. 2008. "Credit constraints and the cyclicality of R\&D investment: Evidence from France," PSE Working Papers 2008-26.

[4] Aghion, Philippe, Stephen Bond, Alexander Klemm, Ioana Marinescu, 2004. "Technology and Financial Structure: Are Innovative Firms Different?," Journal of the European Economic Association, vol. 2(2-3): 277-288.

[5] Almeida, Heitor, Murillo Campello and Michael Weisbach. 2004. "The Cash Flow Sensitivity of Cash" The Journal of Finance Vol. 59.

[6] Angeletos, George-Marios and Calvet, Laurent-Emmanuel, 2006. "Idiosyncratic production risk, growth and the business cycle," Journal of Monetary Economics, vol. 53(6): 1095-1115.

[7] Antunes, Antonio R. and Cavalcanti, Tiago V. de V., 2007. "Start up costs, limited enforcement, and the hidden economy," European Economic Review, Elsevier, vol. 51(1):203-224.

[8] Bachmann, Ruediger, Ricardo J. Caballero and Eduardo Engel, 2008. "Aggregate Implications of Lumpy Investment: New Evidence and a DSGE Model," Cowles Foundation Discussion Papers 1566R.

[9] Bancel, Franck and Usha R. Mittoo, 2004. "Cross-Country Determinants of Capital Structure Choice: A Survey of European Firms," Financial Management, vol. 33(4).

[10] Barlevy, G. B. 2004. "On the Timing of Innovation in Stochastic Schumpeterian Growth Models." NBER WP 10741.

[11] Bates, Thomas W., Kathleen M. Kahle and René M. Stulz, 2009. "Why Do U.S. Firms Hold So Much More Cash than They Used To?," Journal of Finance, vol. 64(5):1985-2021.

[12] Bernanke, Ben S. and Gertler, Mark, 1989. "Agency Costs, Net Worth, and Business Fluctuations," American Economic Review vol. 79(1):14-31.

[13] Bernanke, Ben S., Gertler, Mark and Gilchrist, Simon, 1999. "The financial accelerator in a quantitative business cycle framework," Handbook of Macroeconomics, in: J. B. Taylor and M. Woodford (ed.), volume 1, chapter 21:1341-1393.

[14] Bernstein, Jeffrey I and Nadiri, M Ishaq, 1989. "Research and Development and Intraindustry Spillovers: An Empirical Application of Dynamic Duality," Review of Economic Studies vol. 56(2): 249-67, April.

[15] Bolton, P., and Freixas X. 2000. "Equity, Bonds and Bank Debt: Capital Structure and Financial Market Equilibrium Under Assymetric Information". The Journal of Political Economy, Vol. 108: 324-351.

[16] Caggese, Andrea and Vicente Cuñat, 2008. "Financing Constraints and Fixed-term Employment Contracts," Economic Journal,vol. 118(533): 2013-2046. 
[17] Carlstrom, Charles T and Fuerst, Timothy S. 1997. "Agency Costs, Net Worth, and Business Fluctuations: A Computable General Equilibrium Analysis," American Economic Review vol. 87(5): 893-910

[18] Carlstrom, Charles T and Fuerst, Timothy S. 1998. "Agency costs and business cycles," Economic Theory vol. 12(3) 583-597.

[19] Christiano, Lawrence \& Roberto Motto and Massimo Rostagno, 2010. "Financial factors in economic fluctuations," WP European Central Bank.

[20] Cooley, T. F., Prescott, E. C., 1995. "Economic Growth and Business Cycles." in Frontiers of Business Cycle Research, Cooley, T. F. Editor

[21] Cordoba, Juan-Carlos and Marla Ripoll, 2004. "Credit Cycles Redux," International Economic Review, vol. 45(4).

[22] Froot, Kenneth A, Scharfstein, David S and Stein, Jeremy C, 1993. " Risk Management: Coordinating Corporate Investment and Financing Policies," Journal of Finance, vol. 48(5), 1629-58.

[23] Gertler, M. and Simon Gilchrist. 1993. "The Cyclical Behavior of Short Term Business Lending Implications: for Financial Propagation Mechanisms" European Economic Review Papers and Proceedings, 37, 1993, 623-631.

[24] Gollin, Douglas. 2002. "Getting Income Shares Right," Journal of Political Economy, vol. 110(2): 458-474.

[25] Graham, John, and Campbell Harvey, 2001, "The theory and practice of corporate finance: Evidence from the field", Journal of Financial Economics 60, 187-243.

[26] Himmelberg, Charles P and Petersen, Bruce C, 1994. "R\&D and Internal Finance: A Panel Study of Small Firms in High-Tech Industries," The Review of Economics and Statistics,vol. $76(1) 38-51$.

[27] Holmstrom, Bengt and Tirole, Jean, 1997. "Financial Intermediation, Loanable Funds, and the Real Sector," The Quarterly Journal of Economics vol. 112(3), pages 663-91

[28] Iacoviello, Matteo. 2005. "House Prices, Borrowing Constraints, and Monetary Policy in the Business Cycle," American Economic Review, vol. 95(3), pages 739-764.

[29] Kiyotaki, N. and Moore, J. (1997). "Credit Cycles." Journal of Political Economy, 105(2), 211-248.

[30] Matsuyama, Kiminori. 2007. "Credit Traps and Credit Cycles," American Economic Review, vol. 97(1), pages 503-516.

[31] Moskowitz T.J.; Vissing-Jørgensen A. (2002) "The Returns to Entrepreneurial Investment: A Private Equity Premium Puzzle?" American Economic Review, Vol 92-4: 745-778(34)

[32] Nadiri, M.I., 1993. "Innovations and Technological Spillovers". NBER WP No. 4423

[33] OECD. "Main Science and Technology Indicators" May 2007

[34] Polkovnichenko, Valery. 2003. "Human Capital and the Private Equity Premium." Review of Economic Dynamics, 6(4): 831-45.

[35] Stulz, Rene M. "Optimal Hedging Policies. 1984. " Journal of Financial and Quantitative Analysis, v19(2), 127-140. 
[36] Valentinyi, Akos and Berthold Herrendorf, 2008. "Measuring Factor Income Shares at the Sector Level," Review of Economic Dynamicsvol. 11(4):820-835.

[37] Van den Heuvel, Skander. 2007. "The Bank Capital Channel of Monetary Policy" University of. Pennsylvania, mimeo.

[38] Walde, Klaus and Woitek, Ulrich, 2004. "R\&D expenditure in G7 countries and the implications for endogenous fluctuations and growth," Economics Lettersvol. 82(1) 91-97.

[39] Zeldes, Stephen P, 1989. "Consumption and Liquidity Constraints: An Empirical Investigation," Journal of Political Economy, vol. 97(2): 305-46 